genetics, have had considerable experience in industrial plants.

This book-in spite of its cost-should become a standard reference work for industrial scientists who are interested in using recent genetical techniques in their strain improvement programmes. B. W. BATNBRIDGE

\section{POTATO BREEDING}

\section{Genetics of the Potato}

Solanum tuberosum. By H. W. Howard. Pp. ix +126. (Logos Press, in association with Elek Books: London, March 1970). 60s.

NoBody has contributed more to our understanding of the genetics of the potato than the author of this book. In addition to his own numerous researches he was author of two comprehensive reviews of the subject which are the automatic source references for potato geneticists. The present work is an up to date survey of the cytology and genetics of the tetraploid group of cultivated potatoes. Roughly one half of the 250 references are dated after 1960, the date of the last comprehensive review. The book will therefore take its place with the reviews as an authoritative reference work. All potato geneticists will need a copy and it will no doubt be widely read by students of crop evolution and plant breeders generally.

The work will therefore be widely used and useful. I found the sections on dihaploids (a rapidly developing field of work) and chimaeras (the author's own speciality and the longest chapter in the book) particularly useful. Having said this, however, I must confess to a certain disappointment. The restriction of the field of discussion to the tetraploid cultivars is, in practice, impossible and the diploids are frequently, though incompletely, treated. In fact, the evolution of the tetraploids cannot be considered in isolation from that of the diploids: one's views on the vexed old question of auto or allotetraploidy (or something intermediate) are intimately bound up with one's views of the differentiation and status of the diploids. And the origins of the diploids themselves cannot be considered in isolation from the many difficult problems connected with the differentiation of their putative wild ancestors. On the auto/allo question, the author surveys the known facts and states other people's conclusions but not his own. The same could be said of much of the book: the facts are there, the measured opinions are not. This is a pity because a monograph by an expert should, I think, guide the reader beyond the facts to what seem, at the moment, to be the best conclusions. That some of the conclusions would no doubt be proved wrong hardly matters. In sum, then, another comprehensive updating review to follow the earlier ones would probably have served potato research workers rather better than this useful but slightly disappointing book.

The book is attractively printed, but the covers of the review sopy curled and it is expensive. There are many errors which escaped proof reading. N. W. Simmonds

\section{PLANTS OF CONTRAST}

\section{Nightshades}

The Paradoxical Plants. By Charles B. Heiser, jun. Pp. 200. (W. H. Freeman: San Franciseo and Folkestone, February 1970.) $\$ 5.95 ; 56 s$.

THE author's own research, his travels in Central and South America, and his teaching experience, have equipped him well for the task of writing this excellent book. One should not be misled by the title into thinking that only species of nightshade are dealt with. With a humour as spicy as the subject of his first chapter (peppers), Professor Heiser discusses potatoes and tomatoes, tobaceo and aubergines, the more esoteric lulos and pepinos, and many others in the nightshade family of flowering plants. Their origins, uses and interrelationships are brought under his critical eye, and he shows us that this family is one of contrasts, its members supplying food, narcotics, dyes and condiments, as well as having ornamental uses.

Subjects touched on are as diverse as the species under discussion. In history and archaeology, horticulture and cookery, herbals and modern medicine, genetics and plant breeding, the author engages and enlightens us in a consistently lively style. Particularly praiseworthy is the way that principles from specialized branches of botany are introduced, and explained with great clarity. His own clear thinking is admirably demonstrated in the complicated account of the wonderberry which ends with a fine example of the process of scientific thought from hypothesis through experimentation to deduction. $\mathrm{He}$ obviously has a special interest in the origins of cultivated plants and their spread by man over the Earth because much of the book is devoted to this topic.

The drawings, some copied from herbals and some original, are, in the author's words, "not intended to be models of accuracy but only to give a general impression": with this qualification they are acceptable. There are a few photographs, a short bibliography, and a comprehensive index.

Many harmless solanaceous plants have, in the past, been regarded with suspicion, probably because of the knowledge that they were related to the mandrake, henbane, and others known to be poisonous and evil. The author's enthusiasm for the nightshade family is very infectious, and he blends folklore and anecdote with scientific detail in an interesting and highly readable account that will appeal to both botanist and layman.

A. R. PERry

\section{THE GLORY OF RUBBISH}

\section{Ecology of Refuse Tips}

By A. Darlington. (Scholarship Series in Biology.) Pp. xii $+138+8$ plates. (Heinemann: London, December 1969.) $25 s$.

UNPREPOSSESSING as the local rubbish tip may appear to be, it is, as Mr Darlington has found for himself, a fascinating man-made biotope-a paradise for naturalists who can bear the smell and will brave the broken glass. Even today the tips reveal our social history; thus, a high proportion of potato peelings in winter reflects the need to peel old potatoes, but not the new. The mixture of refuse which comes from our homes and is carted to a tip ensures a very great variety of conditions on the tip; some areas are largely rotting vegetable matter, others covered with an impervious crust of plastic remains, while in some places old iron raises the amount of the metal in the soil water. In addition, numerous habitats, such as old tin cans, domestic mincers and the like, are available. A tip therefore provides many niches for plants and animals.

Capping soil is brought from a distance to cover tips, and with it come the seeds and soil animals. Other seeds are carried on the tyres of the lorries or the boots of the workmen, yet more are wind-borne. Animals, being more mobile, perhaps colonize the tips more quickly. This process of colonization and establishment of species is only one factor which the author and various groups of boys have studied in the twenty-odd years that the author has used rubbish tips as teaching places. He begins his book with a general consideration of the kinds of refuse which go to make up tips and of the soil conditions which arise on them. Then a series of chapters deal with the vegetation, plant dispersal and adaptation to water, aquatic life, terrestrial invertebrates, vertebrates in general and birds in particular. Each chapter has a short list of books for reference and very often the commoner species of plants and animals are illustrated.

Considerable problems are looming close with the great 